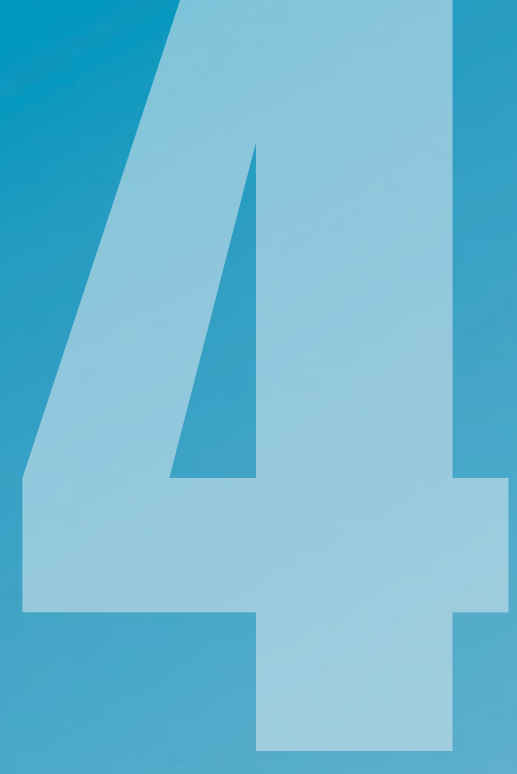

ÁMBITOS

REVISTA

INTERNACIONAL

DE COMUNICACIÓN

$N^{\circ} 46$

EDICIÓN OTOÑO

2019

ISSN: 1139-1979

E-ISSN: 1988-5733

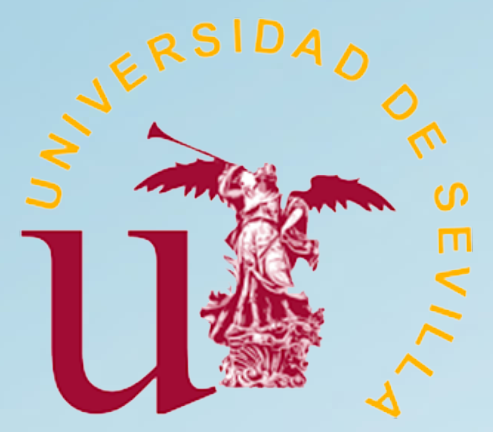




\section{ÍNDICE}

MONOGRAFICOS MONOGRAPHS

Presentación Monográfico. Comunicación emergente. Experiencias para el cambio social

Dra. Nereida López Vidales

Los formatos de televisión más consumidos por los jóvenes: telerrealidad y empoderamiento de la audiencia

Most consumed televisión formats by young people: real TV and the empowerment of the audience Nereida López Vidales, Leire Gómez Rubio, Elena Medina de la Viña

Nuevas herramientas, viejas costumbres El Contenido Generado por los Usuarios sobre el cambio climático en YouTube

New tools, old habits User Generated Content about climate change on YouTube

David Vicente Torrico

Tratamiento periodístico de personas LGTBIQ+ refugiadas: estudio de caso sobre Pride Barcelona 2018

Journalistic treatment of LGTBIQ+ refugees: case study on Pride Barcelona 2018

Hadriel Theodoro, Amparo Huertas Bailén

Tiempo Muerto, estudio de caso de un proyecto transmediático para la consecución de competencias universitarias

Tiempo Muerto, case study of a transmediatic project for the achievement of university competences Jose L. Carreño Villada, Miguel Ángel Díaz Monsalvo

Los universitarios millennials: uso de redes sociales y relación con las marcas

University Millennials: use of social media and engage with brands

Pedro Pablo Marín Dueñas, Esther Simancas González

Ali Ferzat: De la caricatura comunicativa en papel a la caricatura activista en los medios digitales

Ali Ferzat: From political cartoons in papers to political cartoons in digital media

Salud Adelaida Flores Borjabad

Direito à informação e literacia midiática: Reflexões sobre a questão do acesso

Right to information and media literacy: Reflections on the question of acce

Christiane Delmondes Versuti 
Eficacia de los influencers como recurso publicitario en la estrategia de los anunciantes locales Efficacy of influencers as an advertising resource in the strategy of local advertisers

Isabel Iniesta-Alemán

As redes sociais como ferramenta de marketing em instituições de ensino superior no Brasil Social networks as a marketing tool in higher education institutions in Brazil

Alcino Ricoy JR, Rogério Eduardo Rodrigues Bazi

Estudio sobre la conceptualización y el tratamiento informativo de la violencia de género en la prensa digital cubana

Study about the conceptualization and information treatment of gender violence in the Cuban digital press

Regla Ismaray Cabreja Piedra, Karina Escalona Peña

\section{ARTÍCULOS ARTICLES}

Uso de Twitter durante los debates electorales televisados en los comicios andaluces de 2018 The use of Twitter during the televised electoral debates in the 2018 Andalusian elections Julia Fontenla Pedreira, Erika Conde Vázquez, Carmen Máiz Bar

Quem averigua as notícias, os algoritmos ou jornalistas? A lógica crítica de C. S.

Peirce como processo de identificação de uma Fake News

Who checks the news, algorithms or journalists? The critical logic of C. S. Peirce as a

process for identifying a Fake News

Adelino de Castro Oliveira Simões Gala, Vania Baldi, Universidad de Aveiro

\section{RESEÑAS REVIEWS}

Nuevo ecosistema comunicativo digital: El consumidor

Juan Carlos Figuereo Benítez

Corpus toponímic de Beniarrés

Bianca Sánchez-Gutiérrez

The Future Computed. La inteligencia artificial y su papel en la sociedad y Pulsa actualizar. La aventura de redescubrir el alma de Microsoft y concebir un futuro mejor para todos 


\title{
Ali Ferzat: De la caricatura comunicativa en papel a la caricatura activista en los medios digitales
}

\author{
Ali Ferzat: From political cartoons in papers to political cartoons \\ in digital media
}

\author{
Salud Adelaida Flores Borjabad, Universidad de Sevilla \\ C/San Fernando 4, 41004, Sevilla \\ sflores@us.es | Orcid: http://orcid.org/0000-0003-1739-3229
}

DOI: http://dx.doi.org/10.12795/Ambitos.2019.i46.07

\begin{abstract}
Resumen
Ali Ferzat es uno de los caricaturistas más importantes del mundo árabe. Sus caricaturas empezaron como un acto comunicativo que pretendía reivindicar los derechos que no estaban contemplados dentro del mundo árabe. Así, se convirtieron en una válvula de escape comunicativa que expresaba temas que nadie se atrevía hablar por el temor a las represalias. No obstante, la Primavera Árabe supuso una revolución, ya que permitió que irrumpieran las nuevas tecnologías como medio de comunicación. En este sentido, la caricatura se consolidó como medio debido a que su transmisión fue muy veloz, pero también se convirtió en un arte de resistencia que incitaba al activismo social. Por ello, este trabajo pretende mostrar un análisis de las caricaturas de Ali Ferzat, así como también reflejar esta evolución en el género de la caricatura que ha propiciado que se convierta en un puro acto de activismo social capaz de hacer tambalear al régimen. Con todo, se ha utilizado una metodología cualitativa que permita analizar la evolución de las caricaturas, así como también un método visual etnográfico que permita describir las caricaturas y mostrar esa evolución significativa. Por tanto, se trata de reflejar cómo la caricatura se ha consolidado como género comunicativo y medio de comunicación alternativo al entrar en contacto con los medios digitales. Pues, la caricatura es una
\end{abstract}


forma de hacer reaccionar a la sociedad a través del impacto visual, por lo que se convierte en un arte de resistencia idóneo para luchar de forma activa contra el régimen.

\begin{abstract}
Ali Ferzat is one of the most famous cartoonists in the Arab world. His cartoons started as a communicative act which became a communicative valve of relief for society. This fact allowed people to talk about prohibited themes because people could feel fear of the reaction of the regimes. However, the Arab Spring was a revolution which permitted the society to use new technologies as a media. Consequently, political cartoons were consolidated as a media and they became an art of resistance which encouraged people to develop an important feeling of social activism. Therefore, this research is an attempt to address the issue of the analysis of Ali Ferzat's cartoons. Additionally, this research is an study of the evolution of the genre of political cartoons that has been crystalized as an act of activism in Syria and the Arab world. As a result, a qualitative methodology has been used in this research as well as a visual ethnographic method in order to describe, analyze and contextualize Ali Ferzat's cartoons. For this reason, the aim of this research is to study and examine the consolidation of political cartoons as a communicative genre and an alternative media thanks to the contact with digital media. Thus, political cartoons are a form of reaction of the society by using visual impact in order to fight against authoritarian regimes in a peaceful manner.
\end{abstract}

Palabras clave: Dibujo, árabe, medios de comunicación de masas, revolución cultural, identidad cultural.

Keywords: Cartoons, Arab, mass media, cultural revolution, cultural identity.

\title{
1. INTRODUCCIÓN
}

Este trabajo es un análisis de la evolución de las caricaturas de Ali Ferzat como medio de comunicación. Este caricaturista es considerado como uno de los más importantes del mundo árabe. Cuenta con más de 15.000 caricaturas y ha sido galardonado con una gran cantidad de premios. Sus caricaturas se han ido adaptando a los diferentes tiempos, en tanto que son un reflejo de los distintos acontecimientos de su vida. Él nació en el año 1951 en Hama (Siria) y ha tenido la capacidad de conocer diferentes acontecimientos que han sido un referente en sus caricaturas, tales como la llegada del Baaz ${ }^{1}$ al poder, la Primavera de Damasco y la propia Primavera Árabe. En este sentido, sus dibujos son una fuente rica de información que se muestran en dos vertientes: una primera etapa que analiza la situación del mundo árabe en general, por lo que son intercambiables entre los diferentes países; y una segunda etapa tras la Primavera Árabe que supuso un cambio tanto en la temática como en su forma de transmisión. Pues, la caricatura dejó de ser impersonal y universal y pasó a centrarse en Siria y, particularmente, en Bashar al-Asad, siendo todo eso transmitido a través de los medios digitales.

Ámbitos. Revista Internacional de Comunicación | ISSN: 1139-1979 | E-ISSN: 1988-5733, №. 46. (2019) 
De este modo, teniendo en cuenta esto, se han establecido diferentes objetivos. Los objetivos generales son: (1) estudiar las caricaturas de Ali Ferzat antes de la Primavera Árabe; (2) analizar la influencia de la Primavera Árabe; y (3) observar el impacto social. Por otro lado, también se han establecido una serie de objetivos específicos. Éstos son: (1) establecer una relación de temas desarrollados durante la Primavera Árabe; (2) comprobar si han evolucionado y en qué medida han provocado una reacción social; y (3) determinar la nueva forma de transmisión de la caricatura tras el desarrollo de la Primavera Árabe.

En lo referente a la metodología, se ha optado por una aproximación teórica. Por tanto, se ha usado una metodología cualitativa que permita construir una serie de hechos que expliquen y predigan ciertos fenómenos, al mismo tiempo que permitan establecer ciertas generalizaciones. Así, el proceso para realizar ha consistido en recoger, codificar y analizar datos. Luego, se ha establecido una relación entre ellos y se ha desarrollado un proceso de comparación con el fin de establecer un proceso de análisis y síntesis.

Se han utilizado como fuente primaria las caricaturas de Ali Ferzat. Se ha seleccionado una muestra de antes y después de la Primavera Árabe con el fin de compararlas y observar la temática. Para analizarlas, se ha utilizado un método visual etnográfico que permita describirlas y contextualizarlas de una manera más exhaustiva, mostrando el objetivo y la finalidad de cada dibujo analizado. Además de esto, se han analizado diferentes entrevistas realizadas al propio caricaturista a través de diferentes medios con el fin de completar y enriquecer el análisis anterior. Asimismo, se han analizado diferentes fuentes secundarias. Están relacionadas con el estudio de la caricatura árabe en general, así como los distintos acontecimientos desarrollados en Siria y en el mundo árabe. Por tanto, el uso de estas fuentes permite encuadrar también las caricaturas en un periodo histórico determinado que permite observar la evolución de su transmisión.

En lo referente a la muestra, se han aportado 12 caricaturas de Ali Ferzat. Estas caricaturas pueden encontrarse en su antología (Ferzat, 2005), su página web (Ferzat, n. d.) y su perfil de Facebook. Se ha optado por usar estos medios debido a que muchas de las caricaturas que estaban en papel han desaparecido o son de difícil acceso. En cuanto a su selección, debido al gran volumen de piezas de estudio, se ha tenido en cuenta los criterios del autor, así como el impacto social que han tenido dichas imágenes y su difusión en la red, puesto que al estar reflejadas en un medio digital su transmisión ha sido mucho más eficaz, llegando incluso a ser re-publicadas en diferentes medios. Por este motivo, se ha elegido una caricatura del periódico satírico al-Domari (El Farolero) a través de su página web (Ferzat, n. d.), puesto que supuso una revolución dentro de los medios de comunicación sirios, ya que era el primer periódico satírico independiente desde 1963 y fue censurado por dirigir sus críticas al gobierno directamente. Asimismo, se han incluido cinco caricaturas referentes a la primera etapa que son figurativas principalmente y reflejan la universalidad, obtenidas principalmente de la antología 
(Ferzat, 2005) y de su web (Ferzat, n. d.). No obstante, se han añadido seis caricaturas en la segunda etapa, con el fin de ejemplificar los temas que trataba antes y después de la Primavera Árabe, mostrando como la caricatura del papel dio el salto a los medios digitales, produciendo al mismo tiempo un cambio en la temática y un afianzamiento en el desarrollo de los temas. Estas últimas caricaturas han sido recuperadas de su perfil de Facebook, debido a que puede considerarse que son las más actuales.

Con todo, se espera reflejar que las nuevas tecnologías de la comunicación en el mundo árabe permitan desarrollar una comunidad virtual comunicativa. Esta nueva comunidad, además, se ve favorecida por un hecho que permite evitar la censura promoviendo que haya una libertad de expresión en el mundo árabe hasta entonces desconocida. Por tanto, el nacimiento de las caricaturas tras el estallido de la Primavera Árabe no sólo ha permitido que exista una transformación en los medios en los que se transmite, sino que también han proporcionado habilidades sociales que estaban en un estrato subyacente debido a la represión.

\section{PRIMERA ETAPA DE LOS DIBUJOS DE ALI FERZAT: DIBUJOS EN PAPEL}

La primera etapa de Ali Ferzat puede dividirse en dos movimientos artísticos. El primero ${ }^{2}$ representa paisajes, mujeres y centros comerciales, usando como elemento clave una técnica impresionista que no deja indiferente al espectador, debido al contraste que esto supone con sus posteriores caricaturas. No obstante, esta primera etapa también está marcada por una fuerte producción de caricaturas (Ferzat, n. d.).

De este modo, se ha hecho un análisis de esta primera etapa que se desarrolla en las páginas de diferentes periódicos o revistas. Esta primera etapa hace que la caricatura se convierta en una válvula de escape para la sociedad que se diluirá de una manera más específica después de la Primavera Árabe. Como consecuencia, se pretende estudiar cómo las caricaturas de Ali Ferzat se han convertido en un símbolo de la cultura árabe y siria, en particular. Esto se debe a que la caricatura ha tenido un impacto social muy importante que se ha visto consolidado con el desarrollo de la Primavera Árabe, hasta el punto de erigirse como un símbolo de la revolución transmitido a través de los medios digitales.

Ali Ferzat publicó su primera caricatura a la edad de 12 años. Vio la luz cuando estaba en sexto curso en al-Ayyam (Los Días) y apareció bajo un titular sobre la Guerra de Independencia de Argelia. Más tarde, el dueño del periódico le escribió una carta, en la que le pedía que fuera a trabajar a Damasco como caricaturista. Como consecuencia, Ali Ferzat se sintió bastante sorprendido, ya que, según él, no sabía dibujar, pues era un simple estudiante de sexto curso con 12 años de edad. Paradójicamente, dicho periódico fue censurado, por lo que echó el cierre con la llegada del Baaz al poder (Anderson, 2005, pp. 13-15). 
A pesar de esto, Ali Ferzat empezó a trabajar para al-Thawra (La Revolución) ${ }^{3}$ en 1969 (Anónimo, 2006). Estos primeros dibujos mostraban acciones y comportamientos basados en temas generales, como el hambre y la pobreza. Sin embargo, paulatinamente, se hicieron famosos, hasta tal punto que la gente comenzó a comprar periódicos. Por tanto, los primeros atisbos de censura no tardarían en llegar. Algunas veces, el editor jefe del periódico no terminaba de entender el simbolismo, por lo que, una vez que se publicaban, solía recibir llamadas del gobierno. De este modo, tuvo que seguir un nuevo procedimiento a la hora de publicar. Primero, el editor jefe echaba un vistazo al dibujo en sí y si él lo aprobaba, lo mandaba al Director General de Prensa. A continuación, el Director General de Prensa se ocupaba de enviarlo al Ministro de Información, quien controlaba el funcionamiento de los medios de comunicación en el país. Aún así, a veces, como no terminaba de comprender el sentido y la simbología del dibujo, el Ministro de Información permitía que se publicara. No obstante, la sociedad lograba entenderlo con facilidad, debido a que el significado era más simple de lo que parecía, y, como consecuencia, el teléfono volvía a sonar con tono de enfado por parte del gobierno. Por ello, en algunas ocasiones el Director General de Prensa se sentaba con el caricaturista contemplando alguno de sus dibujos con el fin de censurarlos, simplemente porque no quería que volvieran a ocurrir este tipo de cosas (Halasa, n. d.).

Un caso parecido le ocurrió en el año 1977 cuando trabajaba en la revista Usama. En este caso, creó una tira cómica para esta revista que se tituló Los viajes de Ibn Batuta, en la que el mismo Ibn Batuta ${ }^{4}$ era representado con barba y bigote llevando sobre la cabeza un turbante en forma de globo. Entonces, para facilitar su comprensión, se representaron algunos personajes bastante relevantes, tales como Mohammad Ali o Omar Sharif. Estos personajes llevaban un turbante en forma de globo y eran avatares de lbn Batuta que cantaban y bailaban. No obstante, posteriormente, el viajero empuja a su burro al presente, donde se ve minimizado viendo como todo el esplendor se había tornado de forma radical. El resultado de todo esto fue que el director de la revista mandó una carta quejándose por la representación y la radicalización que había hecho el caricaturista del régimen de una manera indirecta (Halasa, 2012, junio, p. 22).

Con todo, la década de los 80 , estuvo marcada por un gran reconocimiento internacional. Así, Ali Ferzat logró publicar para el periódico francés Le Monde (El Mundo) (Editores, 2005, pp. 16-17). Sin embargo, en 1990 volvió a su tierra y comenzó a trabajar en el periódico estatal Tishreen (Octubre) ${ }^{5}$ donde solía publicar sus críticas al régimen sirio de una manera indirecta (Anónimo, 2006). En cualquier caso, en 1996, conoció a Bashar al-Asad, con el que entabló amistad (Bennett, 2012). Fruto de esa amistad, cuando Bashar al-Asad llega al poder en el año 2000, Ali Ferzat abre al-Domari (El Farolero) que era el primer diario satírico independiente desde 1963. Aún así, el caricaturista comenzó a sentirse reprimido por parte del gobierno, debido a una serie de caricaturas que criticaban al presidente y el periódico se vio obligado a cerrar en el año 2003 (Moubayed, 
2006, pp. 532-534). Fue tolerado durante dos años y tres meses en los que hubo dos intentos de arrestar al caricaturista y se presentaron denuncias en los tribunales. Por tanto, Ali Ferzat y su equipo se vieron obligados a trabajar fuera, ya que era la única manera de hacer frente a esta situación (Halasa, n. d.).

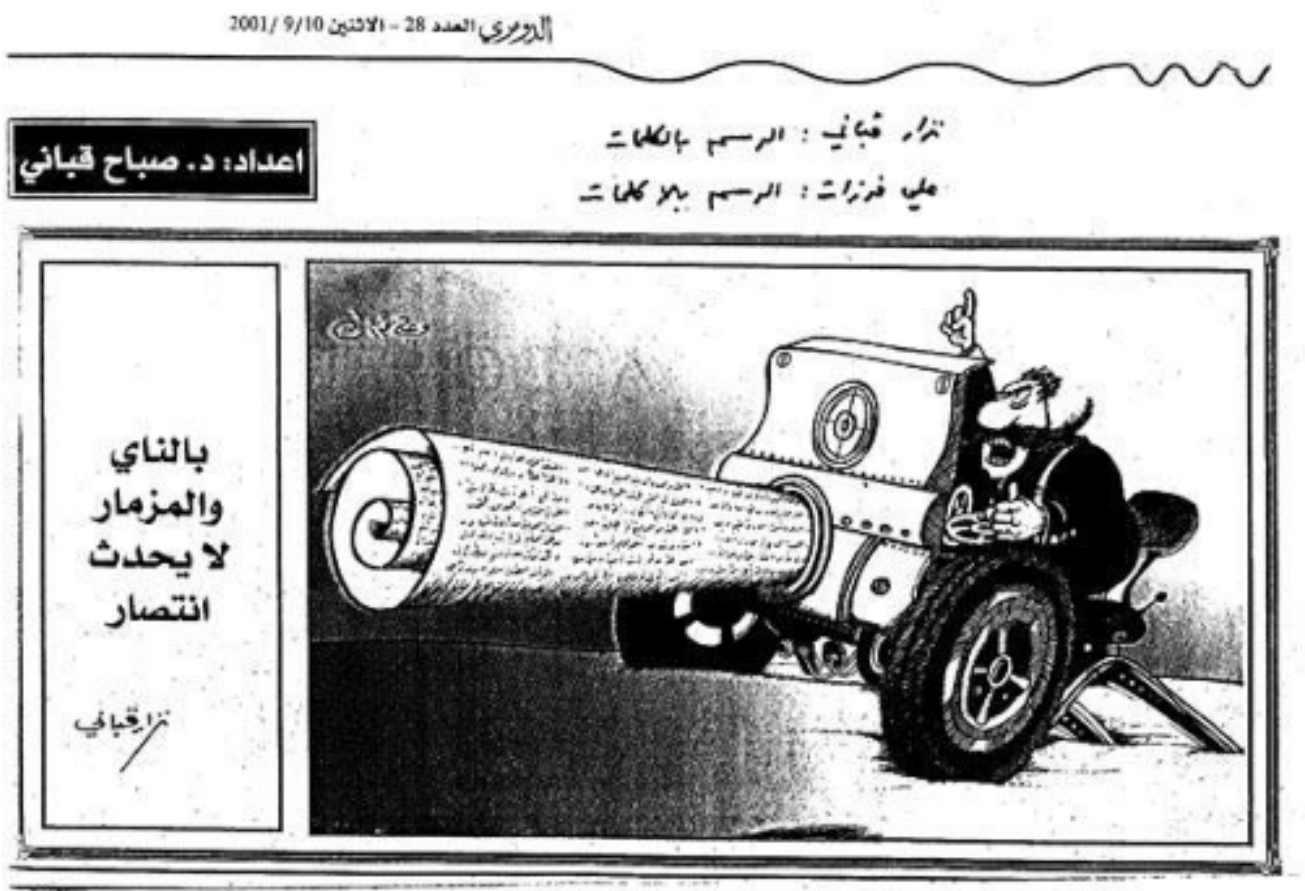

Figura 1. Con cañones no sucede la victoria (Ferzat, n. d.)

En esta caricatura hay un señor con un tanque. No obstante, el cañón es un periódico árabe. Además, el caricaturista añade un poema de Nizar Qabbani cuya traducción literal es <<con la flauta y el oboe no sucede la victoria >>. Así, el texto lo que hace es afianzar el sentido del dibujo. Por tanto, el objetivo es criticar la guerra y afianzar el don de la palabra y los medios de comunicación que pueden vencer con mucha más fuerza y de una manera pacífica.

Sin embargo, a pesar de los intentos de reprimir a Ferzat, éste siguió dibujando y comenzó a publicar sus dibujos en el diario Kuwaití al-Watan (La Nación) (AFP, 2011). Asimismo, en 2005, publicó una antología que se tituló A Pen of Damascus Steel. Political Cartoons of an Arab Master (Una Pluma de Acero de Damasco: Caricaturas de un Maestro Árabe). Estas caricaturas eran universales y aplicables a todo el mundo árabe, por lo que las críticas a los diferentes gobiernos las hacía de manera indirecta. Por ello, 
reflejaban, entre risas y lágrimas, la falta de libertad, democracia, amor y paz que asolaba a estos países, siendo uno de los males contemporáneos (Ferzat, 2005). Se caracterizan por dibujos figurativos y ciudadanos fatigados y opresores avariciosos de manera general sin ponerles un nombre específico, por lo que se acabaron convirtiendo en una parte de la cultura popular siria (Sussman, 2009). Por este motivo, utilizó la escatología para representar al presidente, haciendo ver que criticaba y satirizaba temas generales y aplicables a cualquier gobierno (Wedeen, 2015, pp. 107-111), articulando y renegociando la línea entre gobernante y gobernado a través de la sátira y la parodia (Wedeen, 1995, pp.179-209). Dicho con otras palabras, era una manera de criticar al gobierno haciendo zig-zag (Wedeen, 2015, pp. 111-112), al mismo tiempo que creaba un espacio alternativo en el que los sirios podían ser partícipes. Este espacio, por su parte, permitía a la gente materializar y conmemorar concepciones e ideas de la política siria, puesto que eran capaces de afirmar que el culto a los al-Asad era increíble (Wedeen, 1995: 243-245).

Respecto a la temática, aparecían temas como la injusticia, la represión, los dictadores, el terrorismo, la degradación del medio ambiente y la corrupción, incluyendo todo aquello que degrada las prácticas humanitarias. Por tanto, la intención era aliviar las circunstancias del día a día, es decir, a través de la risa pretendía ayudar a la sociedad a salir del espacio y del tiempo del mundo en el que vivían (Ferzat, 2005, pp.8-9). Así, funcionaban como una válvula de escape que permitía a la gente reírse, al mismo tiempo que iba generando una corriente de opinión (Wedeen, 1995, pp. 174-177). En cualquier caso, la clasificación temática es:

A) Terror y tiranos: Critica las tiranías de los gobernantes, así como el terrorismo. El concepto tiranía y terrorismo están muy unidos, ya que considera que todo aquel que actúa como un tirano es un terrorista, debido a que está oprimiendo a su pueblo. Para reflejar esto, suele utilizar estereotipos relacionados con el terrorismo, tales como bombas, pistolas o personajes enloquecidos, así como también a presidentes financiándolo (Ferzat, 2005, pp. 19-47). 


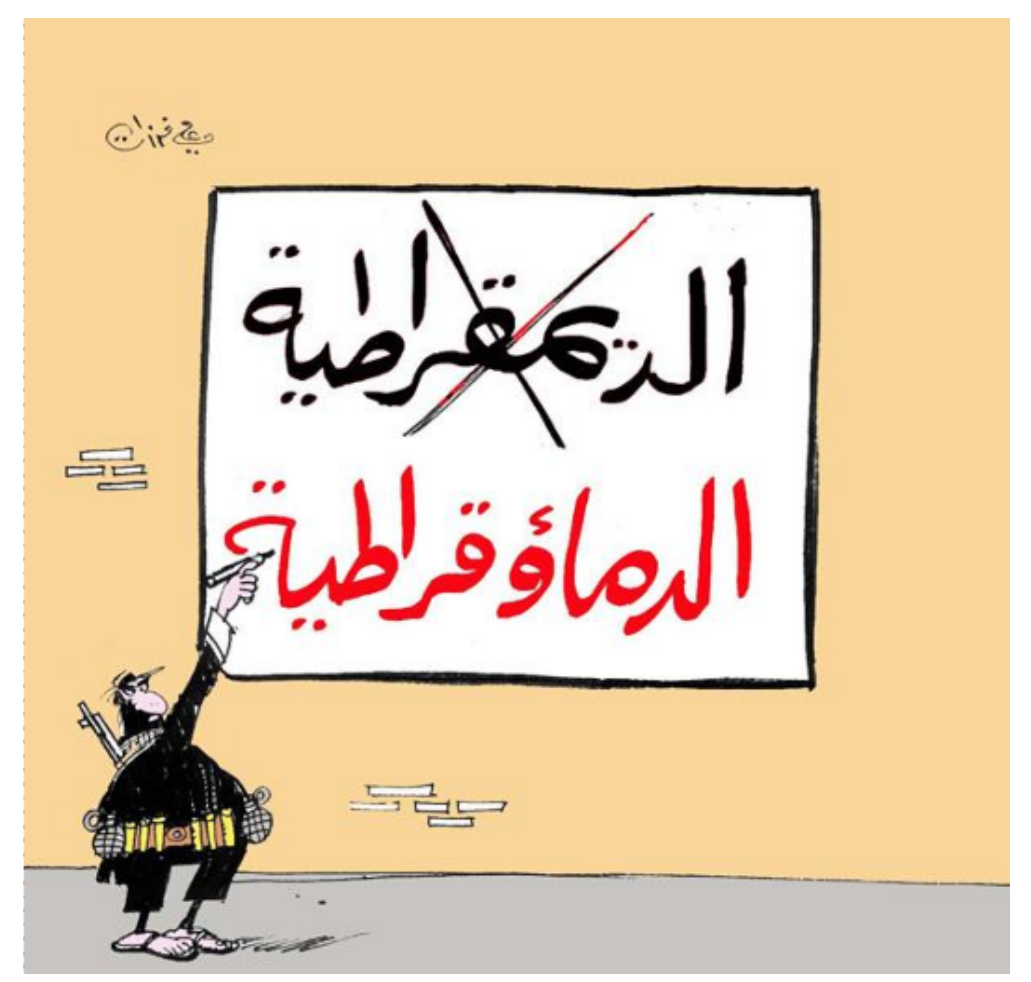

Figura 2. Hemocracia (Ferzat, n. d.)

Aparece en esta caricatura un terrorista armado haciendo un grafiti. Puede verse que tacha la palabra <<democracia >> árabe que está resaltada de color negro y hace un juego de palabras en rojo para referirse a la sangre derramada. Democracia en árabe es $<<$ demoqratiya >> (un calco del griego "el poder del pueblo") y las palabras que añade son $<<$ damau $>>$ (sangre) y <<qratiya $>>$ (poder), por lo que significa "el poder de la sangre". De este modo, pretende señalar que en el mundo árabe no existe una democracia, sino una $<<$ hemocracia $>>$. Por tanto, el objetivo es criticar que no existe ningún tipo de libertad, ya que se ve reprimida por la tiranía ejercida tanto por los presidentes como por los dictadores.

B) Vida: Se relaciona con la humanidad y con la condición del ser humano. Para ello, se critica su hipocresía y su degradación, dado que puede llegar a convertirse en un ser vil y corrupto. Estas caricaturas son un análisis de la doble cara que la especie puede llegar a tener, así como de su capacidad de desarrollar nuevas tecnologías generando una dependencia hasta entonces inexistente. Su idea es mostrar al ser humano en su plenitud, alejándose de cualquier utopía que pueda considerarlo como santo. Considera que hace buenas y malas acciones, según sus propios intereses. De este modo, lo muestra como un ser capaz de corromperse a sí mismo y a los que le rodea con el fin de hacerse con poder (Ferzat, 2005: 49-76). 


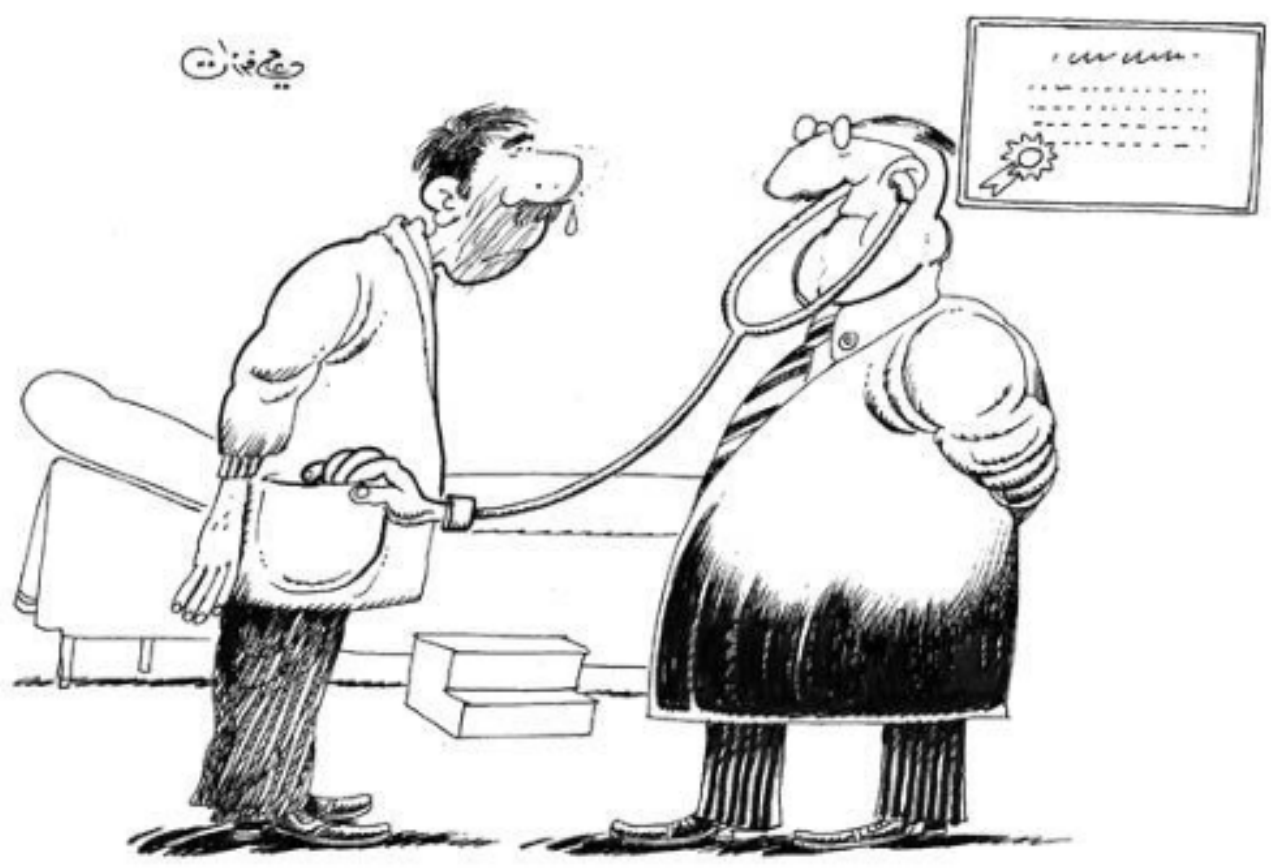

Figura 3. El médico (Ferzat, n. d.)

Hay un hombre asistiendo a la consulta de un médico. Puede verse una camilla y la titulación del especialista colgada en la pared. Sin embargo, el paciente es un hombre con pocos recursos que asiste porque está enfermo. Por otro lado, el médico lleva un traje y lo explora, pero llama la atención que el fonendo va al bolsillo del paciente convertido en una mano que busca dinero incesantemente. Por ello, el objetivo es resaltar como los médicos muchas veces buscan sacar beneficios en vez de salvar vidas directamente; de ahí que sea más importante sacarle el dinero al paciente que curarlo.

C) Gobierno: Son caricaturas políticas, en su mayoría. Ali Ferzat critica los distintos acontecimientos políticos. Tiende a satirizar las cuestiones generales de los distintos gobiernos de forma impersonal. Asimismo, suele reflejar problemas que la sociedad sufre y padece como consecuencia de los diferentes gobiernos y regímenes (Ferzat, 2005, pp. 77-125). 


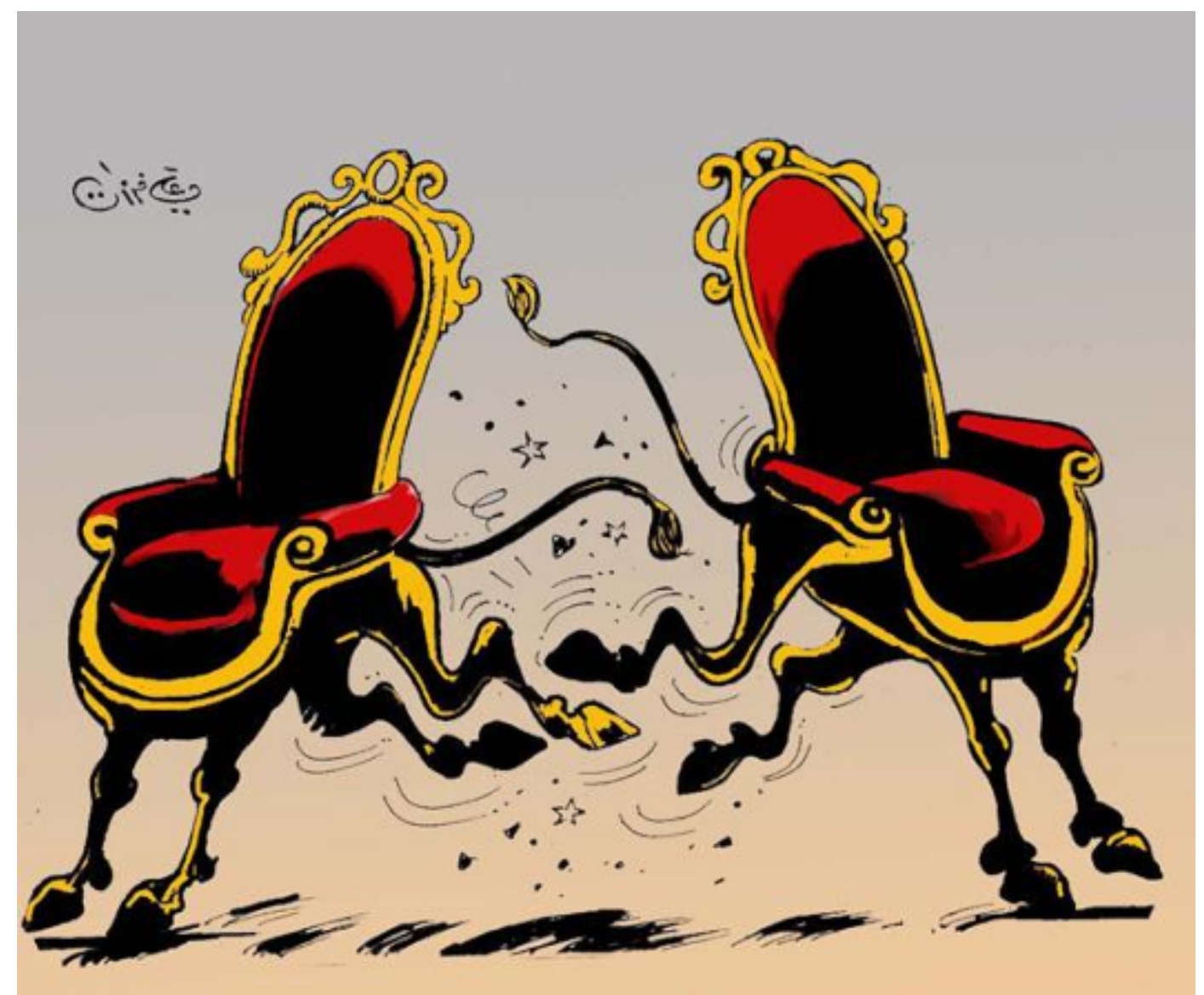

Figura 4. Disputa de tronos (Ferzat, n. d.)

Aparecen en este dibujo dos tronos vacíos que se disputan el poder. Tienen pies de caballo y están peleando constantemente por mantenerse. Por tanto, el objetivo es resaltar que los políticos y los gobiernos no tienen ningún interés social, sino que su verdadera preocupación es afianzarse como los más fuertes en el control del gobierno.

D) Sociedad: Son utilizadas para criticar y analizar los males de la sociedad, dejando a un lado los males políticos. Por este motivo, se han acabado convirtiendo en un símbolo en sí mismas. Esto se debe a que es capaz de transmitir una serie de sentimientos compartidos por todos, tales como el enfado, la risa, el grito que expresa todas las frustraciones y decepciones personales, nacionales y panárabes (Ferzat, 2005, pp. 125-172). 


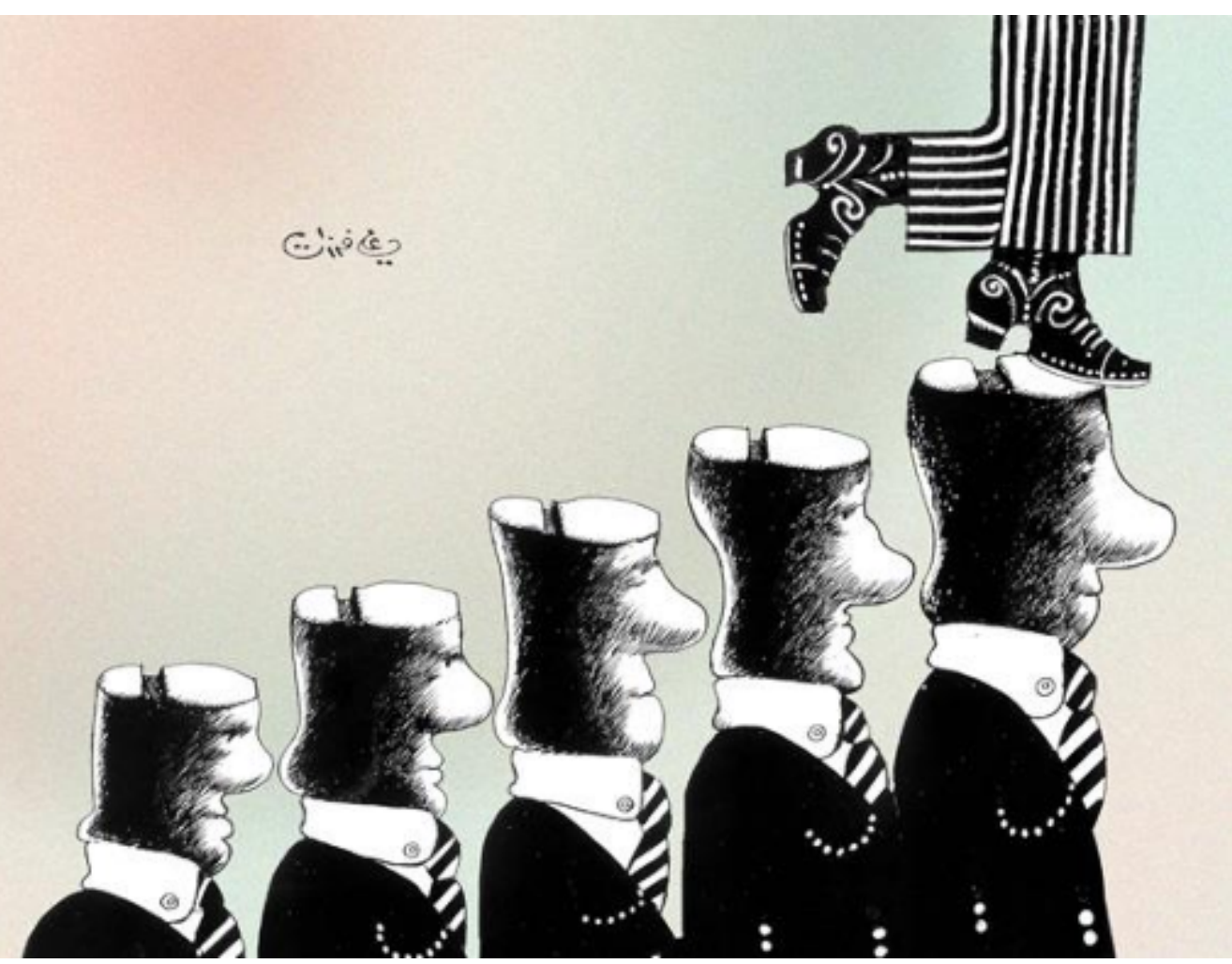

Figura 5. El ascenso al poder (Ferzat, n. d.)

En esta caricatura se representan varios hombres en forma de escalera cuyas cabezas tienen forma de zapato. Esto se debe a que hay otro hombre anónimo (debido a que sólo se le ve los pies) que ha ido pisando esas cabezas hasta dejarlas marcadas con la suela de sus zapatos. Por ello, el objetivo es criticar las formas de ascenso al poder del ser humano que es capaz de cualquier cosa.

E) Problemas mundiales: Tal vez sean las más reflexivas porque afectan al mundo entero. Ali Ferzat se muestra preocupado ante los problemas del medio ambiente, el hambre o la guerra. Sin embargo, son menos numerosas y usuales que el resto que se han analizado (Ferzat, 2005, pp. 173-235). 


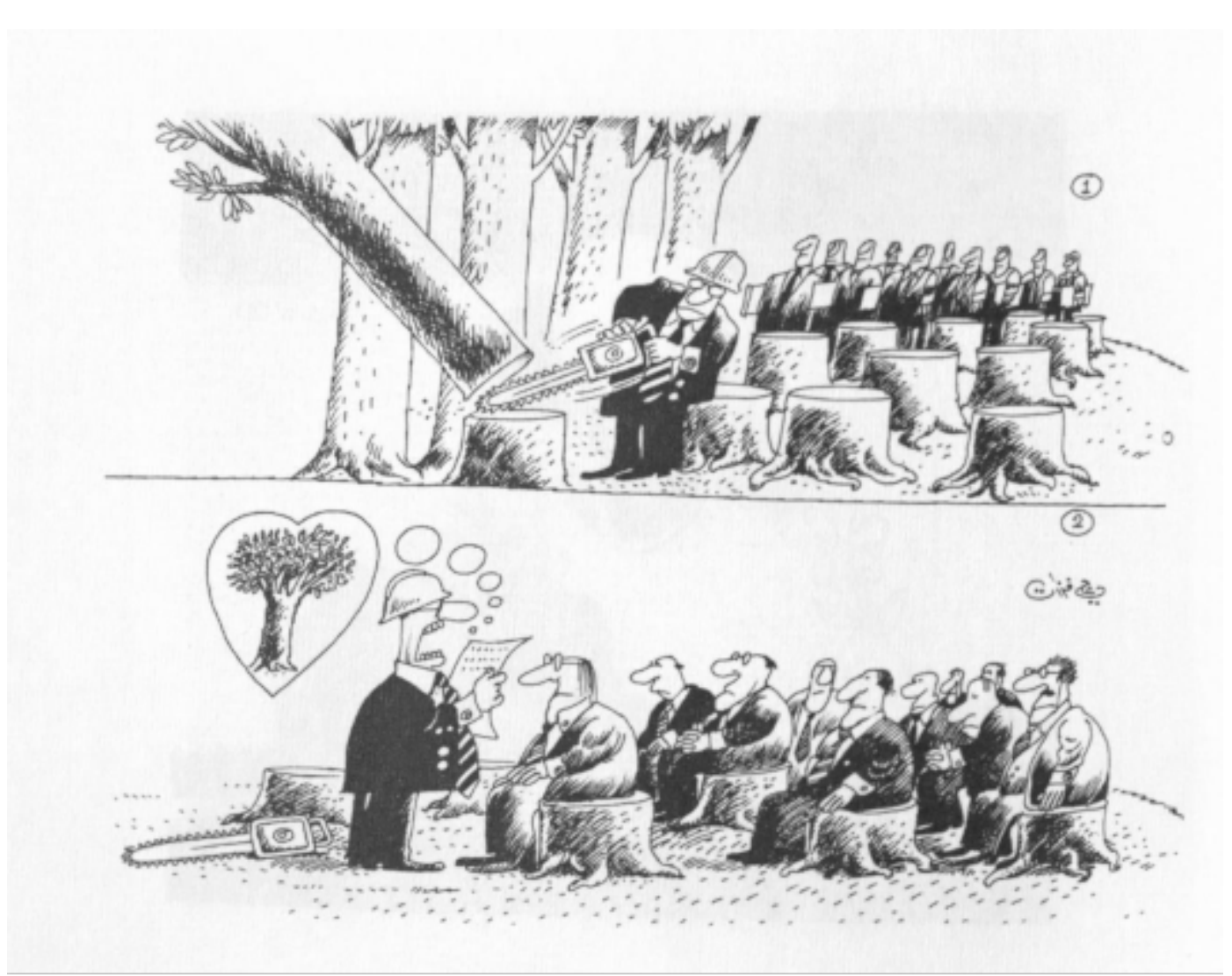

Figura 6. Los árboles (Ferzat, n. d.)

En este dibujo se aprecian dos situaciones bien diferenciadas. La primera muestra a un hombre talando los árboles de un bosque junto con otros observando de forma pasiva la situación, mientras que la segunda representa al mismo hombre dando una charla al resto de personajes sobre el medio ambiente. No obstante, esta charla se hace en el mismo bosque talado y el público está sentado sobre los troncos de los árboles. Por tanto, el objetivo es criticar la hipocresía de los políticos que hablan de cuidar el medio ambiente, que es un problema mundial, cuando en realidad están talando árboles para su propio beneficio.

\section{SEGUNDA ETAPA DE ALI FERZAT: LA CARICATURA EN LOS MEDIOS DIGITALES}

La segunda etapa estuvo marcada por un cambio en la temática y en la intención del caricaturista, así como en el canal de transmisión. Desde siempre, Ali Ferzat buscaba la precisión en el elemento artístico para ofrecer una válvula de escape para la sociedad (Flores, 2018, pp. 208-10). El desencadenante fue el desarrollo de la Primavera Árabe que supuso no sólo una revolución social y política, sino también una transición hacia 
una revolución artística. Este movimiento fue una evocación de un arte contemporáneo que apareció simultáneamente para articular la liberación de la antigua censura, como consecuencia de las restricciones políticas y sociales asociadas al antiguo régimen. Así, se desarrolló un lenguaje visual que combinaba la semiótica, la política y la poética con la incorporación del espectador en la formación del discurso (Shilton, 2013, pp. 129145). Por tanto, la caricatura se convirtió en una manifestación artística y comunicativa que servía de arma propagandística para responder al terrorismo y los actos de guerra, ya que se consolidó como una de las respuestas más visibles, junto con el grafiti (Brianbridge, 2013).

En cualquier caso, esto no hubiera sido posible sin el desarrollo de la sociedad en red y el ciberespacio. Este hecho permitió que se generara una comunicación sintética en red en la que se produjo una interacción por parte de la sociedad a tiempo real. En este sentido, se creó una interconexión entre diversos medios a través del hipertexto de flujos y textos que permitía la fusión de la comunicación interpersonal con la comunicación de masas, obligándolos a entrar en un mundo donde la comunicación les permitía ser autores, emisores o receptores (Cardoso, 2010, p. 154). Por tanto, se generó una forma más interactiva y autónoma que permitía ejercer presión y desafiar a los distintos regímenes autoritarios, gestándose un espacio idóneo para la creación cultural incitando a la sociedad a movilizarse y enfrentarse a las injusticias del régimen (Liu, 2013, pp. 252271). De este modo, apareció una comunidad virtual que desarrolló una forma de acción política en sí misma, funcionando de forma descentralizada, fluida y abierta al mismo tiempo (Carty, 2010, pp. 155-173). En este contexto, las redes sociales cobraron gran importancia para la transmisión de información, dado que incitaban a la movilización política y al activismo social, generando un canal alternativo capaz de romper las fronteras del Estado (Eko, 2012, pp.129-150). Un ejemplo de esto fue el desarrollo de páginas de Facebook realizadas por los activistas con el fin de que la sociedad fuera capaz de dar su opinión sobre lo que estaba ocurriendo. Entre éstas, destacó Syrian Revolution Arts (Artes de la Revolución de Siria) y, en ella, la sociedad mostraba a través de un espacio virtual su ira y su enfado con total libertad y de forma pacífica, ya que muchas de las publicaciones podían hacerse también de manera anónima o con un pseudónimo (Syrian Revolution Arts, 2012).

Así, las caricaturas se transmitieron de una manera mucho más veloz y los temas se ampliaron. En estos dibujos, aparecían los presidentes y los miembros del gobierno representados. Por ello, se transformaron en un acto de activismo que permitía a la sociedad luchar contra las atrocidades del régimen. Este acto fue un avance político y personal, ya que se diluyó la universalidad para representar y comunicar los problemas concretos de cada comunidad, aunque sin abandonar del todo la universalidad (Halasa, 2012, p. 14). Un ejemplo de ello es que se llegaron a encontrar más de 3000 caricaturas 
sobre el Basar al-Asad con el objetivo de reflejar y criticar el cauce que tomó la revolución siria. La expresión de la cara fue cambiando conforme al sentido que iba cobrando la revolución, haciéndolo responsable de todas las atrocidades que se estaban desarrollando en el país (Buha, 2013).

De este modo, Ali Ferzat fue de los primeros en representar al presidente. No obstante, este acto no estuvo exento de represión por parte del gobierno. La noche del 25 al 26 de agosto de 2011 fue secuestrado por parte del gobierno y lo apalearon y lo dejaron semi-inconsciente en una cuneta con los dedos rotos. Aún así, Ali Ferzat logró salvar su vida y, tras reconocerlo, en el hospital lo trasladaron a Kuwait con el fin de que se recuperara. En cualquier caso, empezó a usar la red como medio comunicativo para transmitir las caricaturas, ya que su intención era volver a Siria, pero los hechos se precipitaron y tuvo que seguir luchando desde el exilio. Por tanto, aunque ya había creado una página web en la que publicaba sus caricaturas, utilizó Facebook para seguir su lucha, permitiendo a la sociedad en el proceso político y creativo, así como también haciendo que sus caricaturas dieran la vuelta al mundo (Ferzat, 2012a).

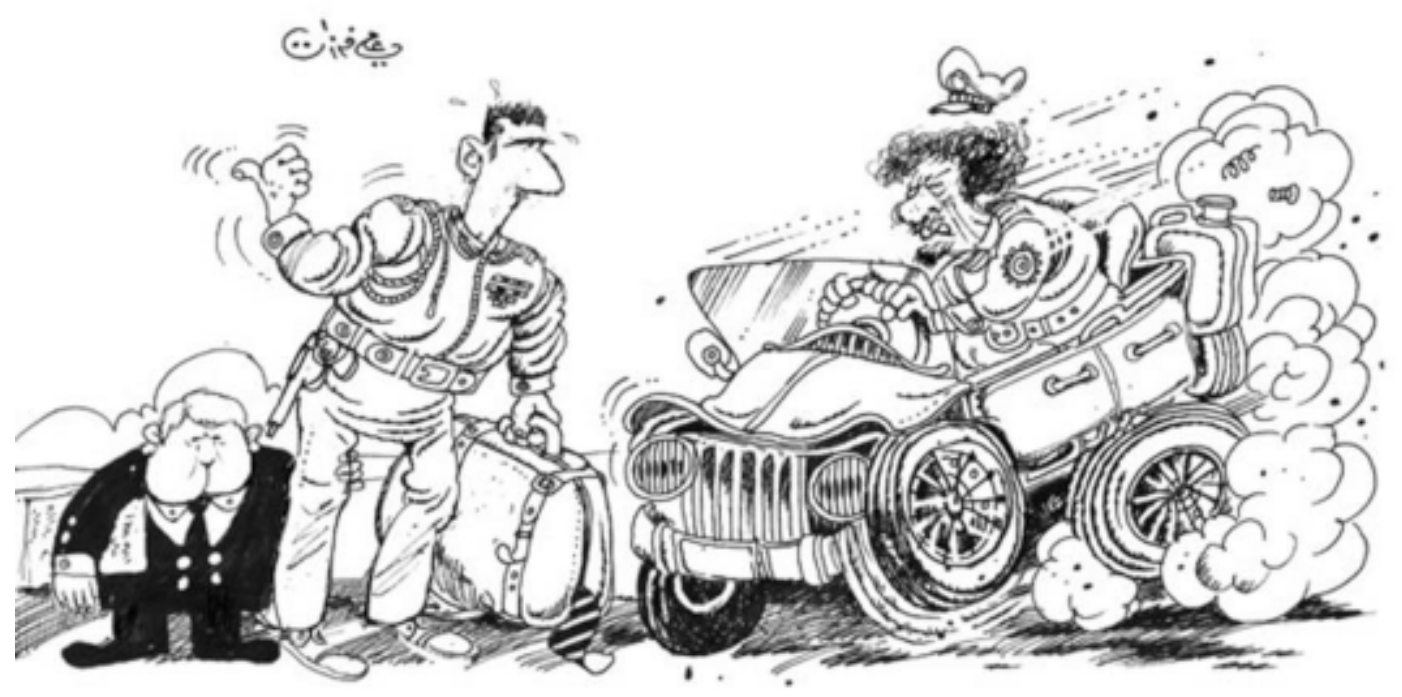

Figura 7. Bashar al-Asad y Gadafi tratando de escapar juntos de sus respectivos países (Ferzat, n. d.)

Esta caricatura fue el desencadenante de la paliza. Se observa a Gadafi (el presidente libio) en un coche saliendo de Libia. Su rostro es colérico y se ve que está nervioso. Asimismo, el coche está acelerado y pierde tornillos debido a la velocidad que lleva. Por 
otro lado, puede verse a Bashar al-Asad, el presidente sirio, que hace auto-stop con el fin de que el otro presidente lo recoja. Al-Asad no está solo, lleva una maleta hecha con prisas y un señor que lo acompaña, como si fuera un sirviente. Por tanto, el objetivo es hacer hincapié en la necesidad de que ambos presidentes se vayan y den paso a la formación de un nuevo gobierno distinto que permita a la sociedad alcanzar las libertades civiles que no han podido alcanzar.

En este sentido, este incidente promovió que se produjera un vuelco en los temas de las caricaturas. Ali Ferzat era consciente de que nada hace desvanecer el miedo como la risa y el sentido del humor, por lo que nada es inmune, ni siquiera las figuras más poderosas (Stoughton, 2012: p. 16). Por ello, decidió romper con todo y llevar esa pequeña revolución artística mucho más allá, puesto que los eventos en Siria contribuyeron a que hubiera un cambio de actitud que le permitió hacer dibujos menos discretos (El-Hasan, 2013). Como consecuencia, aparecieron en las distintas manifestaciones y se convirtieron en un símbolo en sí mismos para luchar contra el régimen (Anónimo, 2013). Por tanto, sirvieron para liberar la mente de la dependencia de una persona o ideología, al mismo tiempo que indicaban que se trataba de un movimiento no violento en el que se reclamaba la libertad de expresión, la libertad de asamblea y revocar el Estado de Emergencia del régimen (Halasa, Omareen y Mahfouz, 2014, pp. 101-108). De este modo, los temas destacados fueron:

A) El presidente sirio: Supuso el principio del cambio. En ellas, se reflejaban los inicios de la revolución a través del rostro del presidente sirio. Su rostro es gracioso y puede provocar la risa al espectador, por lo que el objetivo era ridiculizarlo con el fin de recalcar que la sociedad ya no le tenía miedo y estaba dispuesta a cambiar (Flores, 2018, pp. 328-333). 


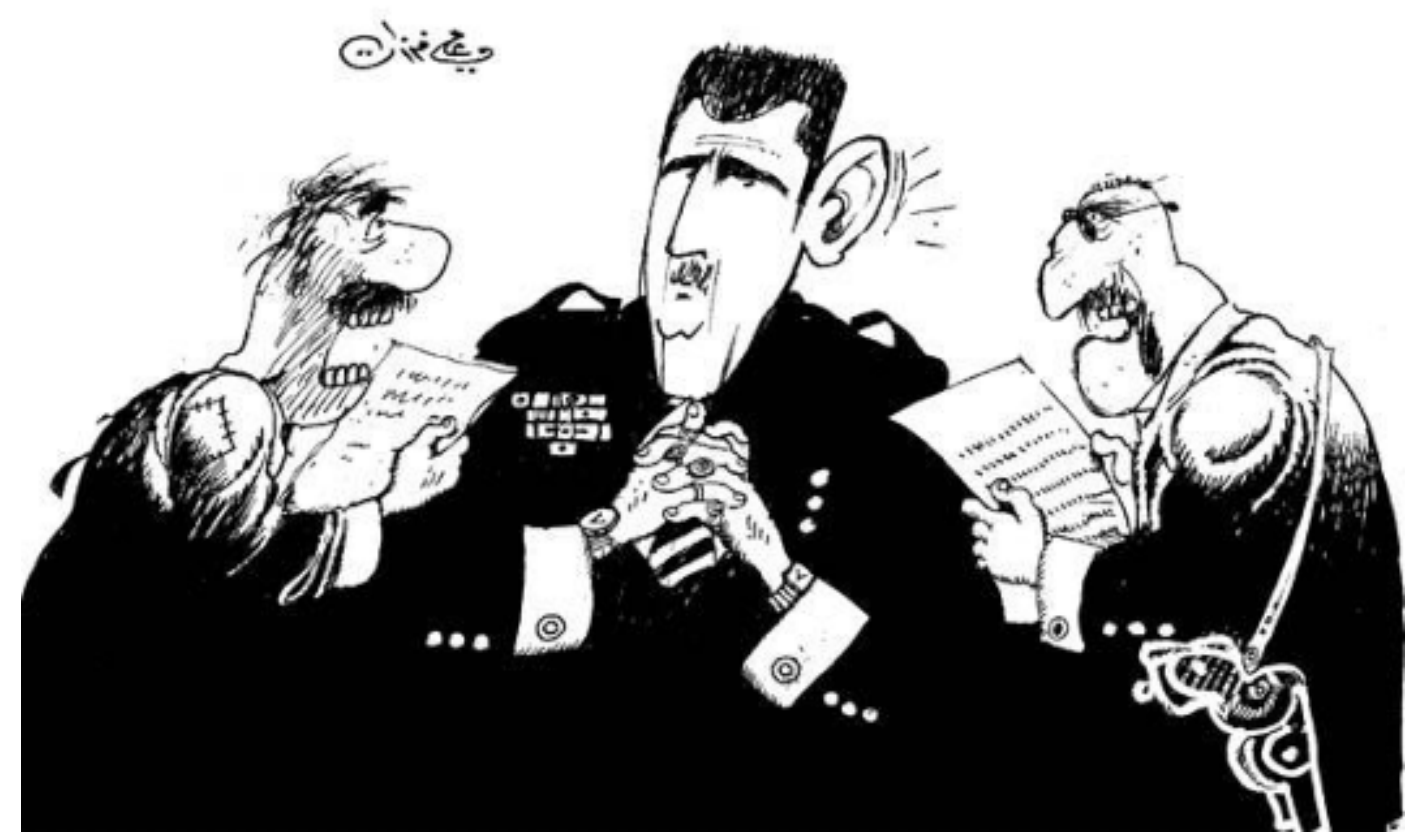

Figura 8. Las propuestas de reforma a Bashar al-Asad (Ferzat, n. d.).

Esta caricatura ridiculiza al presidente sirio. Se observa que en el centro está el presidente y a cada lado hay un personaje diferente. A la izquierda se ve un ciudadano pidiéndole que mejore la situación del país, ya que su ropa está hecha jirones y su rostro se ve cansado. Al lado derecho se aprecia a un oficial ataviado con traje de chaqueta, gafas de sol y una pistola. No obstante, al-Asad presta más atención al oficial hasta tal punto que la oreja derecha es más grande, por lo que las palabras del ciudadano quedan en el aire. De este modo, el objetivo es mostrar que el presidente presta más atención al ejército que a sus ciudadanos, dado que quiere mantener sus privilegios.

B) La guerra de Siria: Tienen un tono más serio y reflexivo. Muestran las consecuencias de la Primavera Árabe siria y la actitud que mostró el presidente ante las manifestaciones. Los protagonistas principales son los niños, aunque también aparece el presidente con un rostro pasivo ante una guerra que se ha cobrado miles de muertes inocentes (Flores, 2018, pp. 333-339). 


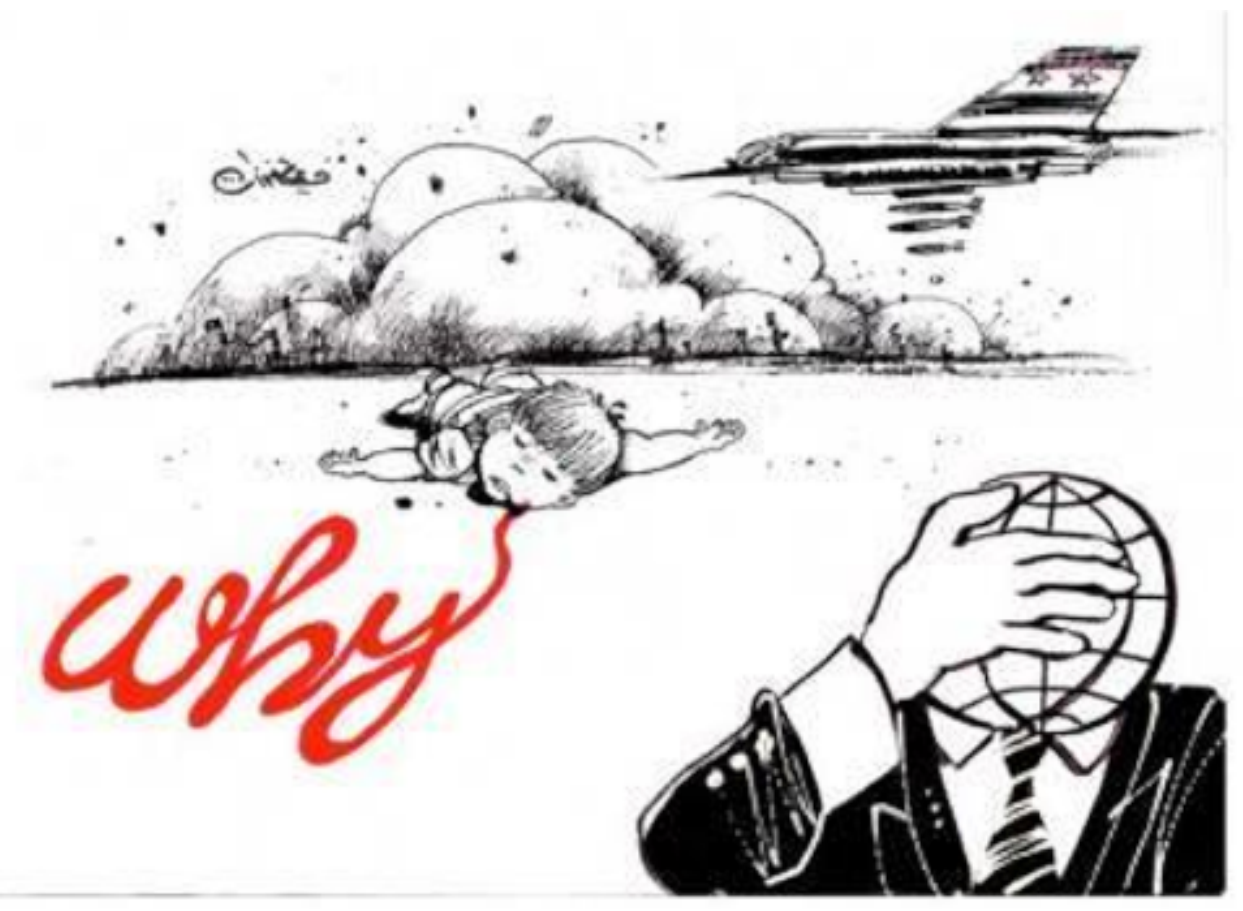

Figura 9. Los niños de la guerra de Siria (Ferzat, 2015a)

En esta caricatura aparece un escenario de guerra. Hay un avión con la bandera siria tirando bombas y destruyendo una ciudad. A continuación, se ve a un niño tirado en el suelo, víctima de esa guerra y de su boca sale un reguero de sangre que forma la palabra why? (¿por qué?). Luego, se observa a un hombre cuya cabeza es la bola del mundo tapándose los ojos ante tales atrocidades. Por tanto, el objetivo es acentuar las víctimas de la guerra a través de ese niño que pregunta por qué le toca morir, mientras el mundo mira hacia otro lado dejando morir a inocentes.

C) La comunidad internacional: Este tema es una consecuencia de la guerra, en tanto que ha dado fuerzas al presidente sirio. Se trata de una crítica a países como Rusia, China, Irán e, incluso, Estados Unidos, en tanto que han permitido la eternalización del conflicto. Por ello, también suele incluir a las Naciones Unidades porque, lejos de solucionarlo, se ha quedado pasiva ante la situación (Flores, 2018, pp. 348-370). 


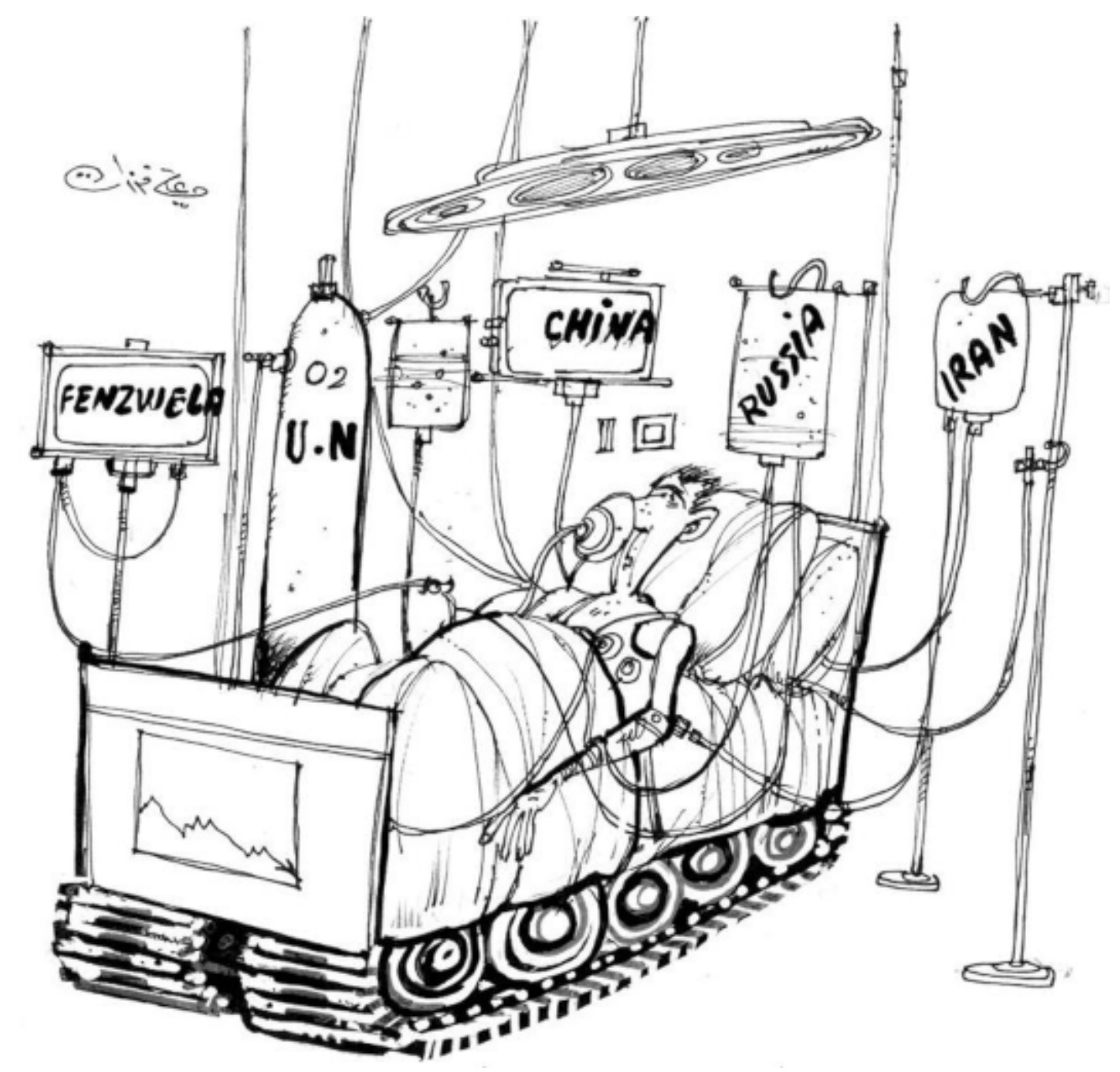

Figura 10. El mantenimiento de Bashar al-Asad (2015b

Esta caricatura representa el mantenimiento de al-Asad en el poder por parte de la comunidad internacional. El presidente aparece en una cama-tanque y alrededor tiene diferentes sueros que lo mantienen con vida. Estos sueros reflejan diversos países tales como Rusia, China, Irán y Venezuela, así como también las Naciones Unidas que, en vez de ser un suero, es la bombona de oxígeno. Así, el objetivo de esta caricatura es criticar la posición internacional respecto al conflicto sirio que mantiene al presidente con vida y con sus propias armas.

D) El terrorismo: Son una consecuencia de las anteriores. El terrorismo afloró en Siria como consecuencia de la guerra civil y de la intervención de la comunidad internacional, que generó un ambiente idóneo para el desarrollo del terrorismo en la zona. Por tanto, estas caricaturas reflejan un rechazo al terrorismo, al mismo tiempo que 
una crítica a la comunidad internacional que lo ha consentido (Flores, 2018, pp. 339348).

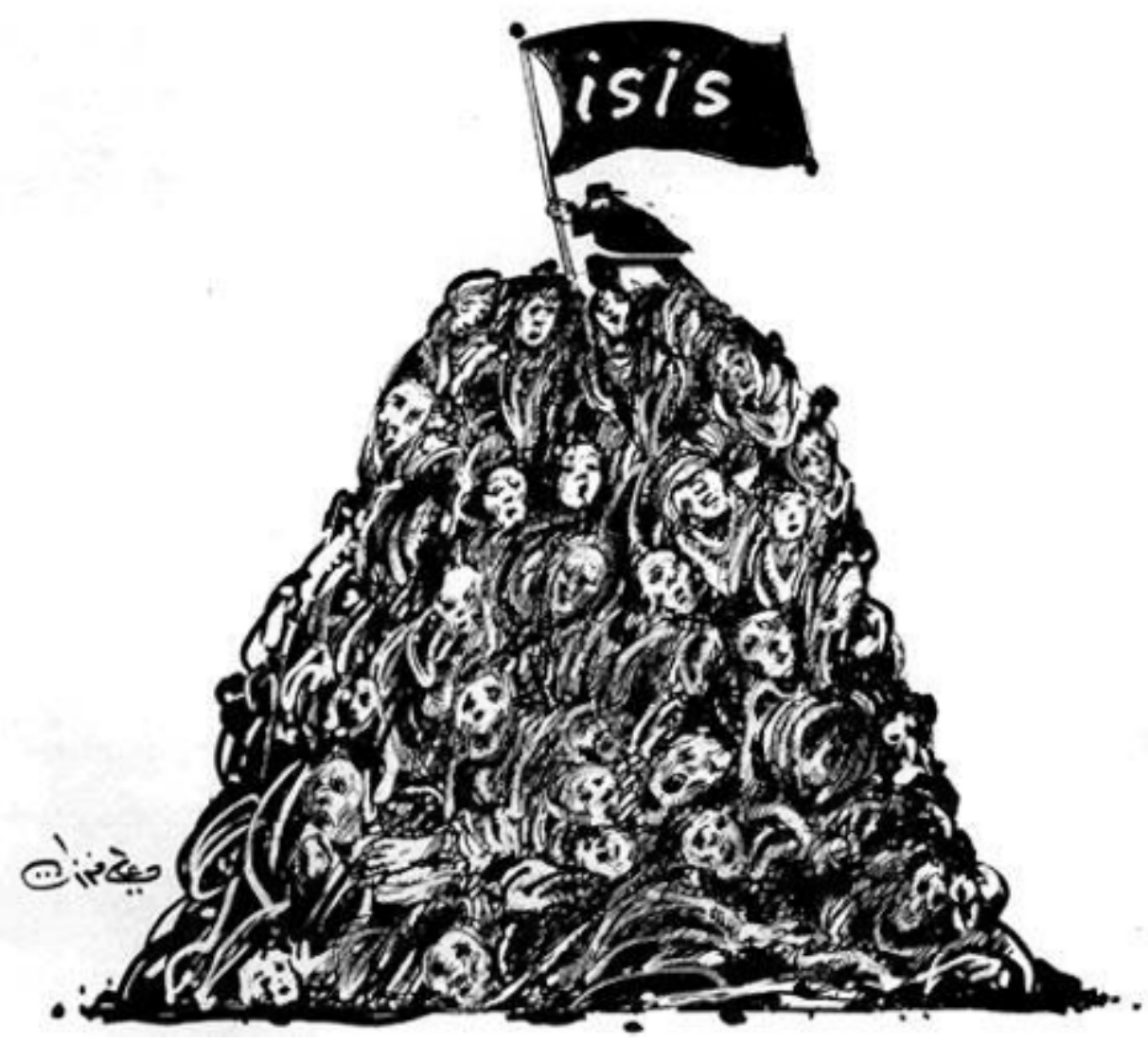

Figura 11. ISIS (Ferzat, 2014)

Esta caricatura muestra una montaña y en la cima hay un terrorista del ISIS colocando una bandera como símbolo de conquista del territorio. No obstante, llama la atención que la montaña la componen los muertos que ha ocasionado este grupo terrorista. Por tanto, el objetivo es criticar a los terroristas que quieren $<<$ conquistar $>>$ territorios en los que se ha derramado la sangre, como ocurre en Siria. Consideran que parte de Siria le pertenece, por lo que han acentuado el daño de la guerra.

E) El triunfo de los medios de comunicación: Este tema, tal vez, sea el más optimista de todos. En él se refleja la necesidad de mantener vivos los medios de comunicación y las caricaturas para seguir luchando contra el conflicto de una manera pacífica. Sin embargo, también muestran el precio que los caricaturistas tienen que pagar por 
ello, dado que son conscientes del poder que tienen sobre la sociedad (Flores, 2018, pp. 370-377).

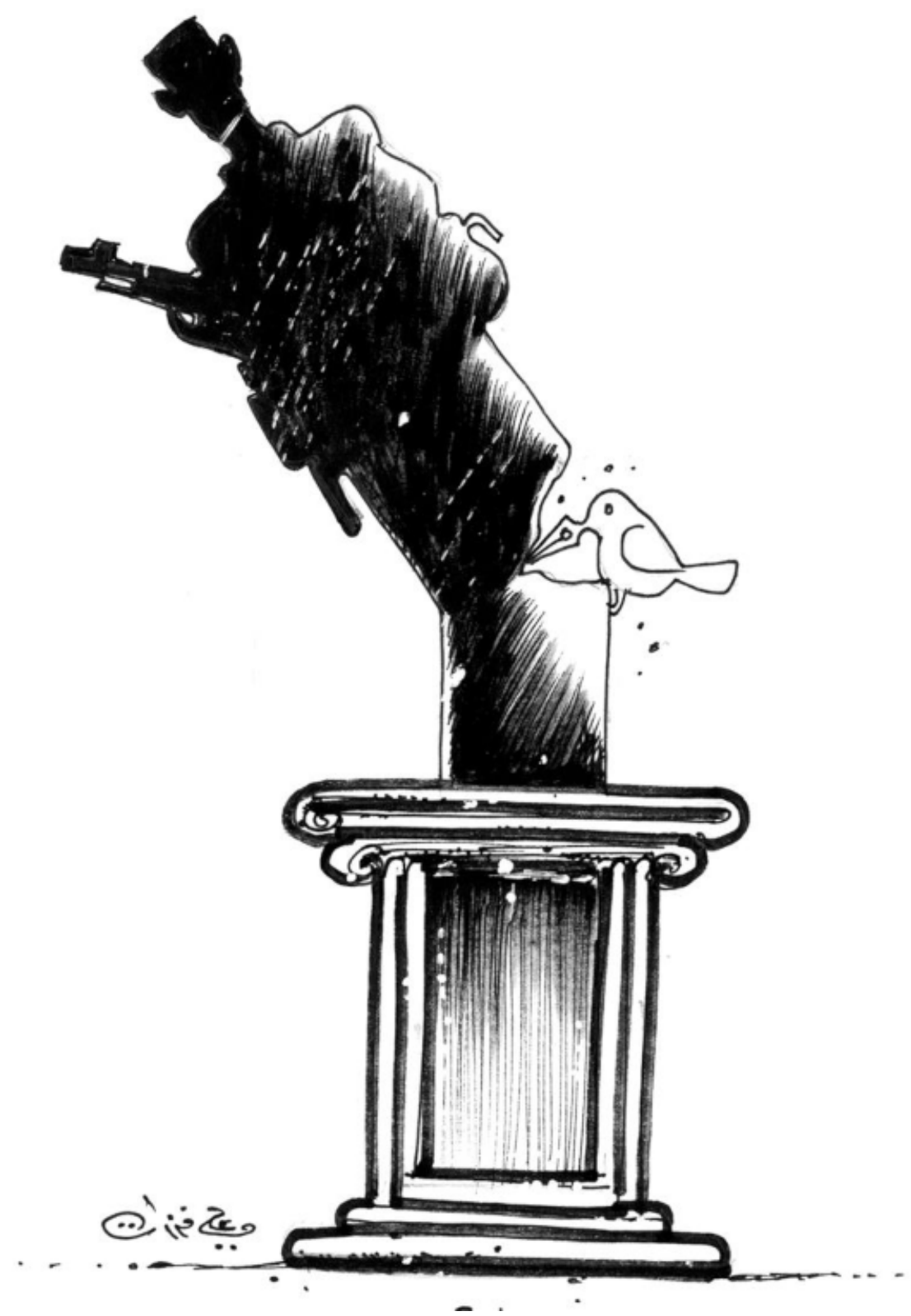

Figura 12. El triunfo de los medios (Ferzat, 2012b)

En esta caricatura hay una escultura con la silueta de Bashar al-Asad, colocada como si fuera un monumento. No obstante, hay un pájaro cuyo pico es una pluma que lo está rompiendo y, como consecuencia, tirando del podio que se sustenta. Por tanto, el objetivo es resaltar el poder de los medios que es mucho más poderoso que las armas y no acaba con la vida de nadie. 


\section{CONCLUSIONES}

Las conclusiones de este trabajo están conectadas entre sí y cada una es una consecuencia de la anterior. En primer lugar, la caricatura es un medio de comunicación capaz de generar cambio en la sociedad, se ha convertido en un símbolo que llega a todos los sectores, propiciando que se convirtiera en un arte de resistencia bastante significativo. Además de esto, ha conseguido ser un componente cultural importante con el que la sociedad se identifica y se une en determinadas circunstancias. Por lo general, ha sido muy poco estudiado porque se ha considerado un elemento que entretiene a la sociedad, por lo que su análisis ha quedado como un elemento secundario dentro de los medios de comunicación que lo relegaban a un mero acompañamiento de noticias. Sin embargo, su desarrollo y afianzamiento como arte de resistencia ha demostrado que su significado puede tener mucho más poder que el de la palabra. Este hecho se debe a que apela al intelecto y a la emoción, recurriendo a un pensamiento creativo que despierta algún tipo de sentimiento en el espectador. Por ello, su uso es mucho más eficaz que cualquier tipo de medio, puesto que es capaz de transmitir una información diferente usando las emociones.

Por otro lado, dentro del mundo árabe, se han desarrollado dos periodos bien delimitados. El primero de ellos es un momento pasivo para la caricatura. Las principales publicaciones se hacían en papel y su difusión, en parte, estaba condicionada por el gobierno. En este sentido, la crítica estaba diluida en la sociedad, es decir, todo el mundo sabía de lo que se hablaba, pero nadie se atrevía a decirlo claramente. Por ello, se convirtieron en una válvula de escape, ya que las diferentes metáforas visuales ayudaban a crear un mundo paralelo. Asimismo, era también una búsqueda de identidad árabe, dado que eran universales y todo el mundo podía sentirse identificado con estas críticas.

No obstante, el desarrollo de la segunda etapa coincide con el desarrollo de la Primavera Árabe. Este punto fue esencial en tanto que los caricaturistas definieron sus críticas y se convirtieron en activistas de la información usando el humor político como arma. Por ello, es un periodo activo en el que la sociedad participó en dicho proceso creativo, interactuando con el propio caricaturista. Esto fue también condicionado por el desarrollo del ciberespacio y la sociedad red que promovieron un espacio idóneo para crear un sentimiento de identidad y cultural, al mismo tiempo que proporcionaban las herramientas necesarias para interactuar. Así, el desarrollo de los teléfonos inteligentes, las redes sociales y las diferentes aplicaciones permitió que su transmisión fuera mucho más veloz. Del mismo modo, esta situación permitía generar una opinión alternativa al régimen, en tanto que los usuarios podían participar con sus comentarios, al mismo tiempo que las distribuían por la red. Por este motivo, el medio digital promovió que llegara a más lugares y que todo el mundo se hiciera eco de lo que estaba pasando. 
Este hecho propició que evolucionaran los temas. El desarrollo de la virtualidad en el mundo árabe hizo que desapareciera la censura y que los caricaturistas pudieran publicar libremente. De este modo, empezaron a aparecer personajes reconocibles que todo el mundo identificaba con facilidad. Además, se publicaban en el exilio, en tanto que era más sencillo romper los controles del gobierno, ayudando a que su difusión fuera más eficaz.

Con todo, la caricatura se convirtió en un arte de resistencia y en un medio de comunicación bastante popular en la esfera digital que aún sigue evolucionando y adaptándose a los tiempos. Como consecuencia, los sectores más jóvenes de la sociedad se sintieron identificados y los utilizaron como moneda de cambio contra el régimen. Por tanto, la caricatura fue una forma de comunicación capaz de generar cambio y aún le queda mucho por hacer, puesto que se ha convertido en un espacio mundial donde las críticas y la participación ciudadana no tiene límites.

Aún así, la caricatura no ha dejado de evolucionar. La caricatura puede ser considerada como una parte esencial de la cultura que se adapta a los nuevos tiempos y medios para expandirse. La risa es algo que ha acompañado al ser humano y tiene diferentes formas de manifestarse y transmitirse. Este hecho es así hasta tal punto que Ali Ferzat en la actualidad continúa dibujando y ampliando sus horizontes de publicación. Prueba de ello es que muchas de sus caricaturas no aparecen exclusivamente en Facebook, sino que se han abierto nuevos horizontes conforme a los gustos y experiencias de la sociedad. De este modo, puede verse que muchos de sus trabajos están apareciendo muy recientemente en Instagram haciendo referencia al eterno conflicto y a la necesidad de liberar a Siria de ese cruel invierno que parece no tener fin. Por este motivo, es muy importante seguir investigando y analizando el hecho de la caricatura como forma de expresión artística y comunicativa que se adapta a las necesidades de una determinada sociedad y cultura y que al mismo tiempo pretende ser global gracias al desarrollo de los nuevos medios digitales; pues puede ser un elemento determinante para analizar elementos comunicativos, culturales y sociopolíticos. 


\section{Notas}

1. El Baaz es un partido socialista árabe fundado en 1947. Dicho partido político llegó a Siria en 1963 y se acabó consolidando con Hafez al-Asad en 1970.

2. Ali Ferzat comenzó sus estudios de Bellas Artes en la Universidad de Damasco en 1970 (Anónimo, 2006). No obstante, lo tuvo que dejar a los tres años para hacer el servicio militar, aunque él mismo siguió dibujando, prácticamente a escondidas (Taleb, 2005: pp. 14-17).

3. Al-Thawra (La Revolución) es uno de los periódicos oficiales del gobierno sirio. Incluye iniciativas gubernamentales tanto en materia social y económica. Actualmente, sigue funcionando en plataformas digitales (al-Thawra, n. d.).

4. Ibn Batuta fue un viajero andalusí de la época meriní que destacó por su tratado de viajes. La utilización de Ibn Batuta, en este caso, está relacionada con el hecho de que la época de alAndalus, así como el periodo abbasí fue considerado un momento de esplendor para el desarrollo de la ciencia, la literatura y la sabiduría, en general.

5. Tishreen (Octubre) es otro periódico afín al régimen sirio. Al igual que al-Thawra (La Revolución), el objetivo es ensalzar y alabar el régimen, por lo que se convierte en un medio idóneo para la propaganda y la legitimidad al presidente (Tishreen, n. d.).

\section{Referencias}

AFP (2011). Arab Spring Provides Inspiration to Regional Cartoonists. Al-Arabiya. Recuperado de https://bit.ly/2MJURxE

al-Thawra (n. d.). al-Thawra. Recuperado de https://bit.ly/2lfA299

Anderson, B. (2005). Comedy. Preface. En 'A. Farzāt (Ed.) A Pen of Damascus Steel. Political Cartoons of an Arab Master. Seattle: Cune Press

Anónimo (2006). Ali Farzat. Cune Press. Recuperado de https://bit.ly/2WJq74w

Anónimo (2013). A 'pain in the Assad?' Syrian cartoonist speaks out from exile. Al-Arabiya. Recuperado de https://bit.ly/2xy3rrP

Bennett, O. (2012). The moral dilemmas of Syria's revolution. BBC. Recuperado de https://bbc.in/2WHzvpf

Brianbridge, L. (2013). In place of war: Egypt's artists after the Arab Spring. The guardian. Recuperado de https://bit.ly/Mv3KXV 
Cardoso, G. (2010). Los medios de comunicación en la sociedad en red: filtros, escaparates y noticas. Barcelona: Editorial UOC.

Carty, V. (2010). New information communication technologies and grassroots mobilization. Information, Communication and Society, 13:2, pp. 155-173. Recuperado de https://bit.ly/2KMpSOO

Editores (2005). On Titles and Notes. Preface. En 'A. Farzāt A Pen of Damascus Steel. Political Cartoons of an Arab Master. Seattle: Cune Press.

Eko, L. S. (2012). New Media, Old Regimes. Case Studies in Comparative Communication Law and Policy. Lanham, Maryland: Lexington Books.

El-Hasan, J. (2013). Art, revolution and Ali Ferzat. The Daily Star. Recuperado de https://bit.ly/2ZoAh7y

Ferzat, A. (n. d.). Ali Ferzat. Recuperado de https://bit.ly/2srv7tf

Ferzat, A. (2005). A Pen of Damascus Steel. Political Cartoons of an Arab Master. Seattle: Cune Press.

Ferzat, A. (2012a). Syrian cartoonist Ali Farzat: 'They broke my hands to stop me drawing Assad' - video. Drawing the Revolution The Guardian. Recuperado de https://bit.ly/2KirDE1

Ferzat, A. (2012b). Fotos de Ali Ferzat. Ali Ferzat. Facebook. Recuperado de https://bit.ly/2Xd8k5d

Ferzat, A. (2014). Fotos de Ali Ferzat. Ali Ferzat. Facebook. Recuperado de https://bit.ly/2WKwZOW

Ferzat, A. (2015a). Fotos de Ali Ferzat. Ali Ferzat. Facebook. Recuperado de https://bit.ly/2ZxPBir

Ferzat, A. (2015b). Fotos de Ali Ferzat. Ali Ferzat. Facebook. Recuperado de https://bit.ly/2XcdCOs

Flores, S. (2018). La Siria de Ali Farzat: la caricatura en el mundo árabe. (Tesis Doctoral Inédita). Sevilla: Universidad de Sevilla.

Halasa, M. (n. d.). Ali Ferzat in his own words. Arab British Centre. Recuperado de https://bit.ly/2CIII62

Halasa, M. (2012, junio). Creative dissent. Index on Censorship. Vol. 41 Issue 2, p14- 25.

Halasa, M., Omareen, Z. y Mahfouz, N. (Eds.) (2014). Syria speaks: art and culture from the frontline. Londres: Saqi Books.

Moubayed, S. M. (2006). Steel \& Silk: Men \& Women Who Shaped Syria 1900- 2000. Cune Press. 
Shilton, S. (2013). Art and the Arab Spring: Aesthetics of revolution in contemporary Tunisia. French Cultural Studies, 24 (I), pp. 129-145. Bristol, UK: Sage.

Stoughton, I. (2012). Syrian artists make drawings, not bombs. McClatchy - Tribune Business News. Recuperado de https://bit.ly/2XaHCtP

Sussman, A. (2009). Drawing the line between editorial and cartooning: The Guardian's Steve Bell and An-Nahar's Armand Homsi discuss the art and science of their trade. The Daily Star. Recuperado de https://bit.ly/2KiPOIM

Syrian Revolution Arts (2012). Facebook. Recuperado de https://bit.ly/2Jb2nvt

Taleb, B. (2005). Wisdom. Preface. En 'A. Farzāt A Pen of Damascus Steel. Political Cartoons of an Arab Master. Seatle: Cune Press.

Tishreen (n. d.). Tishreen. Recuperado de https://bit.ly/2INcXtk

Wedeen, L. (1995). The Politics of Spectacle: Discipline, Resistance, and National Community in Syria. Berkeley: University of California.

Wedeen, L. (2013). Ideology and Humor in Dark Times: Notes From Syria. Critical Inquiry. 39. 4. Chicago: The University of Chicago.

Wedeen, L. (2015). Ambiguities of Domination. Politics, Rhetorics, and Symbols in Contemporary Syria. Chicago: The University of Chicago Press. 


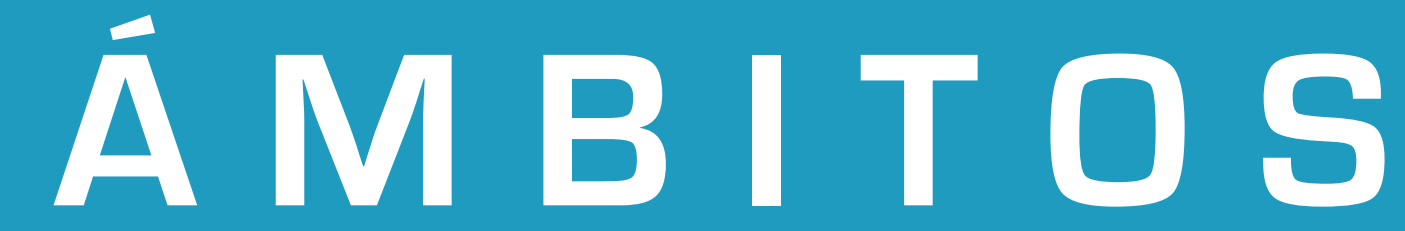

ISSN: 1139-1979 | ISSN digital: 1988-5733 | Depósito Legal: SE-1493-98

Revista Internacional de Comunicación editada por el Grupo de Investigación en Estructura, Historia y Contenidos de la Comunicación(GREHCCO) de la Universidad de Sevilla.

\section{ambitoscomunicacion@us.es}

http://institucional.us.es/ambitos

@RevistaAmbitos 